\title{
Adsorption Aspects, Inhibitory Properties and a Study of Surface Corrosion of Carbon Steel in Acidic Media
}

\author{
Qhatan, A. Yousif ${ }^{1} \&$ Adel, A. Al-Zhara ${ }^{1}$ \\ ${ }^{1}$ Department of Chemistry, College of Science, Al-Qadisiya University, Qadisiya, Iraq \\ Correspondence: Qhatan A. Yousif, Al-Qadisiya University, Qadisiya, Iraq. Tel: 9-6478-1311-2362. \\ E-mail: drqhatanscience@yahoo.com
}

Received: May 4, 2016

Accepted: May 25, 2016

Online Published: July 4, 2016

doi:10.5539/mas.v10n10p82

URL: http://dx.doi.org/10.5539/mas.v10n10p82

\begin{abstract}
The impact of cupral compound on steel in presence of deaerated $0.25 \mathrm{M} \mathrm{H}_{2} \mathrm{SO}_{4}$ and $0.5 \mathrm{M} \mathrm{HCl}$ acidic solutions at $298.15 \mathrm{~K}$ was examined by employing electrochemical measurements. It has been observed that the corrosion efficiency increased by increasing of cupral concentration of the corrosion inhibitor and this enhanced the inhibitory action as mixed type inhibitor. Several different adsorption models were examined which indicate the adsorption of cupral compound as inhibitor on the carbon steel electrode surface follows the Langmuir isotherm equation. The thermodynamic factors governing adsorption, as well as the parameters of kinetics corrosion have been estimated. The role of nanosilica has been observed to reduce the values of current density of corrosion process and this was confirmed by study the surface morphology of electrode via SEM-EDX and AFM techniques by formation a protective layer on carbon steel electrode.
\end{abstract}

Keywords: cupral, X65-steel, corrosion inhibition, AFM, acidic solution, SEM-EDX

\section{Introduction}

Iron's alloys are amongst the most important materials in the world because of the good characteristics and varied applications in which they are used (Alaoui, M. et al., 2014). This is especially true of carbon steel, which is one of the low steel, high-strength alloys, that is frequently used in offshore drilling platforms, agitators, pipelines, and tanks, etc. (Preethi et al., 2013). Carbon steel is used on a large scale as a building material for the pipe work in the gas and oil manufacture, for instance the tubular bottom of the well, the flow lines, and pipelines transfer (Okafor et al., 2010). It is an integral part of the equipment used in the oil and other manufacturing industries (Alaoui et al., 2014) and is particularly important because of its easy availability and low cost, making it possible to use it in the fabrication of complex and large-scale installations. This is also the case in water pipes (Jawich et al., 2012), cooling water, boiler and process industries, oil and gas, refining and extraction system, etc. (Ostovari et al., 2009). Corrosion of carbon steel is a big problematic in gas manufacturing industry, especially in oil pipes and this has caused significant economic losses for some countries ( $\mathrm{Li}$ et al., 2012). Acidic media are the most problematic to deal with from the perspective of corrosion as the building and materials industries often use an acid solution to eliminate scale and salts from the surface of steel alloys as well in the cleaning process for storage tanks and pipelines (Panossian et al., 2012). Organic compounds are thus applied as inhibitors to avert corrosion of metals, which is a great concern (Obayes et al., 2014). Organic compounds that have functional groups containing lone pairs of electrons are the best corrosion inhibitors for metals (Morad, 2008).

Previously, researchers have studied used sodium diethyl dithiocarbamate (cupral) as an inhibitor for the CuNi10Fe alloy in seawater (saline solution) (Aljinovi et al., 2000). In other studies dithiocarbamate has been found to inhibit the bronze alloy TM23 corrosion in $0.1 \mathrm{~N} \mathrm{HNO}_{3}$ solution (D'Ars de Figueiredo et al., 2013). Furthermore, the inhibition of the corrosion of brass by using sodium diethyl dithiocarbamate in $3 \% \mathrm{NaCl}$ medium was investigated by Liao (Liao et al., 2011). The present work aims to investigate the inhibitory effect of cupral compound and nanosilica on the corrosion of carbon steel in deaerated $0.25 \mathrm{M} \mathrm{H}_{2} \mathrm{SO}_{4}$ and $0.5 \mathrm{M} \mathrm{HCl}$ acidic solutions by using electrochemical methods. The surface of X65-Steel will be inspected by atomic force microscopy (AFM), scanning electron microscopy (SEM) as well as Energy dispersive X-rays analysis (EDX) to evaluate the composition of protective layer. 


\section{Experimental Details}

\subsection{Solutions and Materials}

The X65-steel (carbon steel) specimen was taken from Iraq's oil fields and had the following composition, as revealed by optical emission spectroscopy (PMI MASTER Pro2 Oxford, UK) shown in Table 1. The pipe was cut, using an electrical hack saw, into a number of test samples of appropriate size with dimensions $(1 \mathrm{~cm} \mathrm{x} 1 \mathrm{~cm})$ and thickness $(1 \mathrm{~cm})$. The samples polished to mirror finish, using emery paper. Usually, the samples were finally polished on a soft cloth with diamond paste as a polishing material using drops of lubricating oil. Afterwards, the specimens were degreased using hot benzene and acetone and dried under nitrogen.

Table 1. Chemical composition of carbon steel (X65-steel) by Optical Emission Spectroscopy

\begin{tabular}{ccccccccc}
\hline Elements & $\mathrm{C}$ & $\mathrm{Si}$ & $\mathrm{Mn}$ & $\mathrm{Cr}$ & $\mathrm{Mo}$ & $\mathrm{Ni}$ & $\mathrm{Cu}$ & $\mathrm{Fe}$ \\
\hline Wt.\% & 2.180 & 3.100 & 1.360 & 0.102 & 0.127 & 0.213 & 0.596 & Balance \\
\hline
\end{tabular}

To prepare the working (X65-steel) electrode, X65-steel was covered with a cured epoxy resin, so that its cross-sectional area, $1 \mathrm{~cm}^{2}$, was in contact with the solution. Experiments were carried out at constant temperature $25.15 \pm 1^{0} \mathrm{C}$ by using a calibrated thermostat water bath circulator (from HYSC Company). The solutions for all the experiments were prepared freshly with doubly distilled water, in sulfuric acid and hydrochloric acid (which were supplied by the Scharlau company). $0.25 \mathrm{M} \mathrm{H}_{2} \mathrm{SO}_{4}$ and $0.5 \mathrm{M} \mathrm{HCl}$ solutions were prepared by dilution of an analytical reagent grade $(97 \%) \mathrm{H}_{2} \mathrm{SO}_{4}$ and $36 \% \mathrm{HCl}$ with doubly distilled water. A study was made of the inhibitory action of cupral (SIGMA-ALDRICH Company) and $\mathrm{SiO}_{2}$ nanoparticles (obtained from the Nanjing Nanotechnology Company with $23 \mathrm{~nm}$ particle size and $96.7 \%$ purity) towards the corrosion of carbon steel in acidic solutions. Experiments were carried out in $0.25 \mathrm{M} \mathrm{H}_{2} \mathrm{SO}_{4}$ and $0.5 \mathrm{M} \mathrm{HCl}$, in the absence and presence of various molarities of cupral (from $1 \times 10^{-3} \mathrm{M}$ to $3 \times 10^{-3} \mathrm{M}$ ) and with the addition of silica nanoparticles $(0.05 \mathrm{~g})$ into the aggressive medium with cupral $\left(6 \times 10^{-4} \mathrm{M}\right)$, whose chemical structure of the investigated compounds is given below:

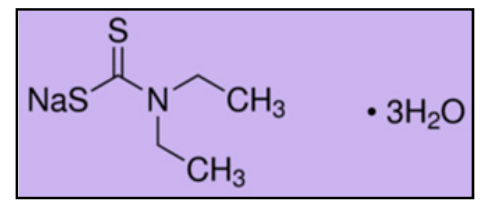

Figure 1. The chemical structure of cupral inhibitor

\subsection{Electrochemical Measurement}

In order to conduct the electrochemical measurements (to obtain both open circuit potential and potentiodynamic polarization curves) the arrangement used was a five neck Pyrex glass cell, containing three electrodes, including a working electrode (the carbon steel under study), a platinum electrode as an auxiliary electrode and a saturated Calomel electrode $\left(\mathrm{Hg}\left|\mathrm{Hg}_{2} \mathrm{Cl}_{2(\mathrm{~s})}\right| \mathrm{KCl}\right)$ as a reference. The remaining two necks, allowed the ingress and egress of nitrogen gas (99.99\% purity). The working electrodes were made of carbon steel which was held using the epoxy resin with a square surface area of $1 \mathrm{~cm}^{2}$. The platinum auxiliary electrode was prepared from a high purity rod stock; a platinized auxiliary electrode was used in the experiments due to its large surface area and high catalytic activity, The saturated Calomel electrode is usually brought in contact with the electrolyte through a glass tubing known as a "Luggin capillary" and the tip of the Luggin tube is placed in the corrosion cell in close proximity to the carbon steel after filling it with test solution to minimize the IR drop effect (Li et al., 2012). Afterwards, the working electrode, auxiliary electrode and reference electrode, with a Luggin capillary, were immersed in the test solution in the corrosion cell and connected to the Potentiostat/Galvanostat Research Grade Interface 1000 (GAMRY company, USA). In all the experiments at various inhibitor concentrations of the test media, the solution was deaerated by bubbling nitrogen gas through it for $1 \mathrm{~h}$ before measuring a potentiodynamic polarization curve. The carbon steel electrode was allowed to corrode freely and record an open circuit potential as a function of time for $10 \mathrm{~min}$. Subsequently, potentiodynamic polarization measurements were scanned from the cathodic to the anodic direction at a scan rate of $3 \mathrm{mv} / \mathrm{s}$. Later, the Tafel polarization curves were analyzed and fitted using an Echem Analyst (version 6.23) to obtain the electrochemical parameters for each polarizing value $\pm 100 \mathrm{mV}$ with respect to the potential value for free corrosion (E VS SCE). The above-mentioned steps were repeated for each measurement. 


\subsection{Surface Analysis}

The surface of the X65-steel was studied before and after having exposure to $0.25 \mathrm{M} \mathrm{H}_{2} \mathrm{SO}_{4}$ and $0.5 \mathrm{M} \mathrm{HCl}$ acidic solutions, both in the absence and the presence of the concentration of the inhibitor $\left(3 \times 10^{-3} \mathrm{M}\right.$ cupral $+0.05 \mathrm{~g}$ nanosilica) at $25.15 \pm 1^{\circ} \mathrm{C}$. The surface was examined by SEM (Type ZEISS sigma300, Germany) at a resolution of $2.2 \mathrm{~nm} @ 1 \mathrm{kV}$, a maximum scan speed of $100 \mathrm{~ns} /$ pixel, and an accelerating voltage $(0.02-30 \mathrm{kV})$. The SEM was linked with Energy Dispersive Spectroscopy (EDS) Analysis (Oxford Instruments, UK) to study and determine the composition of the cover film on the electrode surface. Atomic force microscopy (AFM, AA3000, Angstrom Advanced Inc. USA) was employed at a resolution of: $0.26 \mathrm{~nm}$ (lateral) and $0.1 \mathrm{~nm}$ (vertical) and precision of $50 \mathrm{~nm}$ to study and examine the carbon steel surface. The samples washed gently in distilled water before being dried and examined without further treatment.

\section{Result and Dissuasion}

\subsection{Potentiodynamic Polarization Curves}

As cited in the electrochemical measurement section, special attention was given to the stability of open circuit potential value (OCP) before the potentiodynamic polarization scan was recorded. The measurement of the variation of OCP values of the carbon steel electrode with time is also significant to define kinds of corrosion inhibition, both incomplete and comprehensive inhibition as well as determining the inhibitor concentrations (Shams, E. D. et al., 1997). This means that the open circuit potential gives a clear means to understand the interference of metals that are immersed in solution and is especially sensitive to the addition of inhibitors (Li \& Fedkiw, 2007). In order to study the kinetics of the corrosion process, which includes both the cathodic and anodic reactions that occur on the carbon steel, the electrode was immersed in $0.25 \mathrm{M} \mathrm{H} 2 \mathrm{SO} 4$ and $0.5 \mathrm{M} \mathrm{HCl}$ acidic solutions at concentrations $6 \times 10-4 \mathrm{M}$ of cupral in the absence and presence of nanosilica $(0.05 \mathrm{~g})$ at $298.15 \mathrm{~K}$. The data obtained from the polarization measurements are shown in Figures 1 and 2. The parameters associated with electrochemical kinetics, corrosion current density (Icorr), corrosion potential (Ecorr), and Tafel constants are listed in Table 2. There are slight changes in the OCP towards the negative direction at the different concentrations of inhibitor. This behaviour can be attributed to the adsorption - desorption equilibrium process for the inhibitor molecules on the surface of the electrode (Badawy et al., 2006).

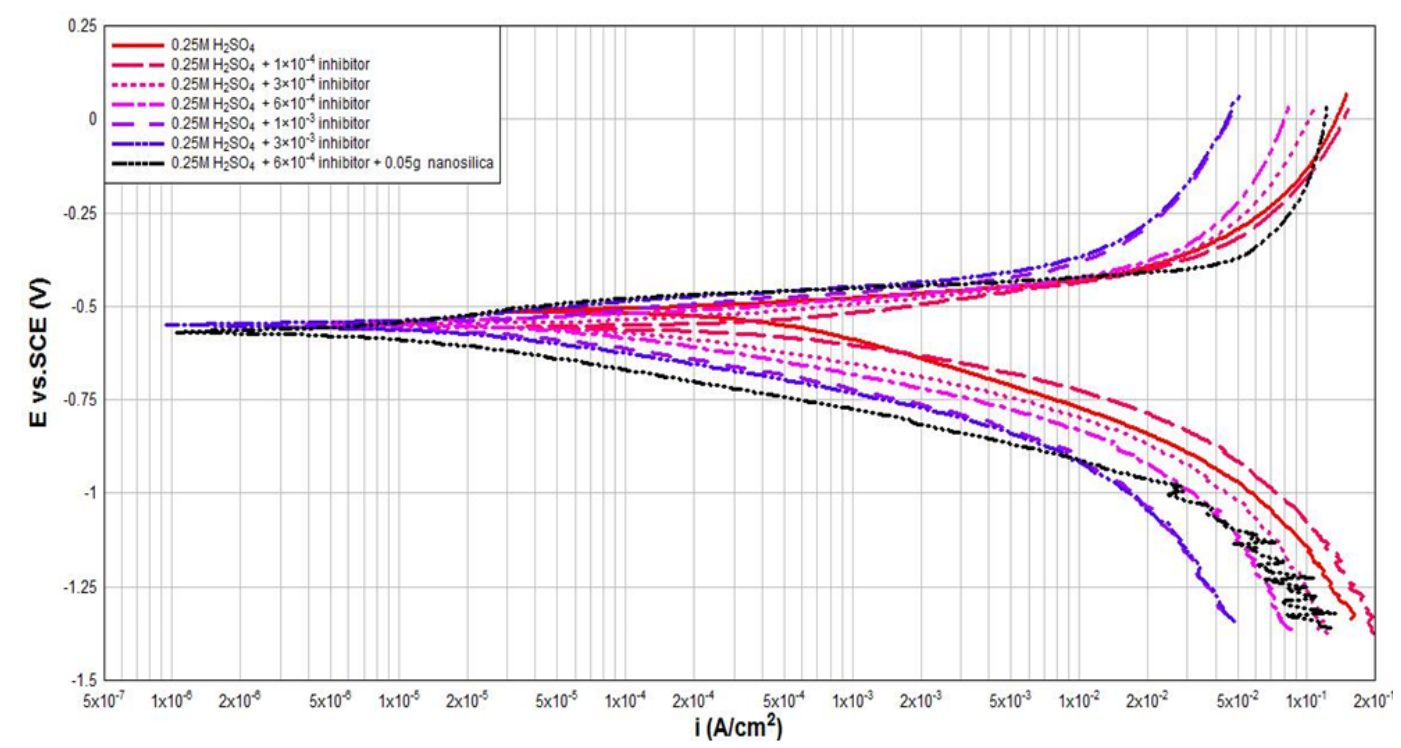

Figure 2. The potentiodynamic polarization curves of carbon steel in deaerated $0.25 \mathrm{M} \mathrm{H}_{2} \mathrm{SO}_{4}$ with and without cupral inhibitor as well as in the presence of silica nanoparticles at $298.15 \mathrm{~K}$ 


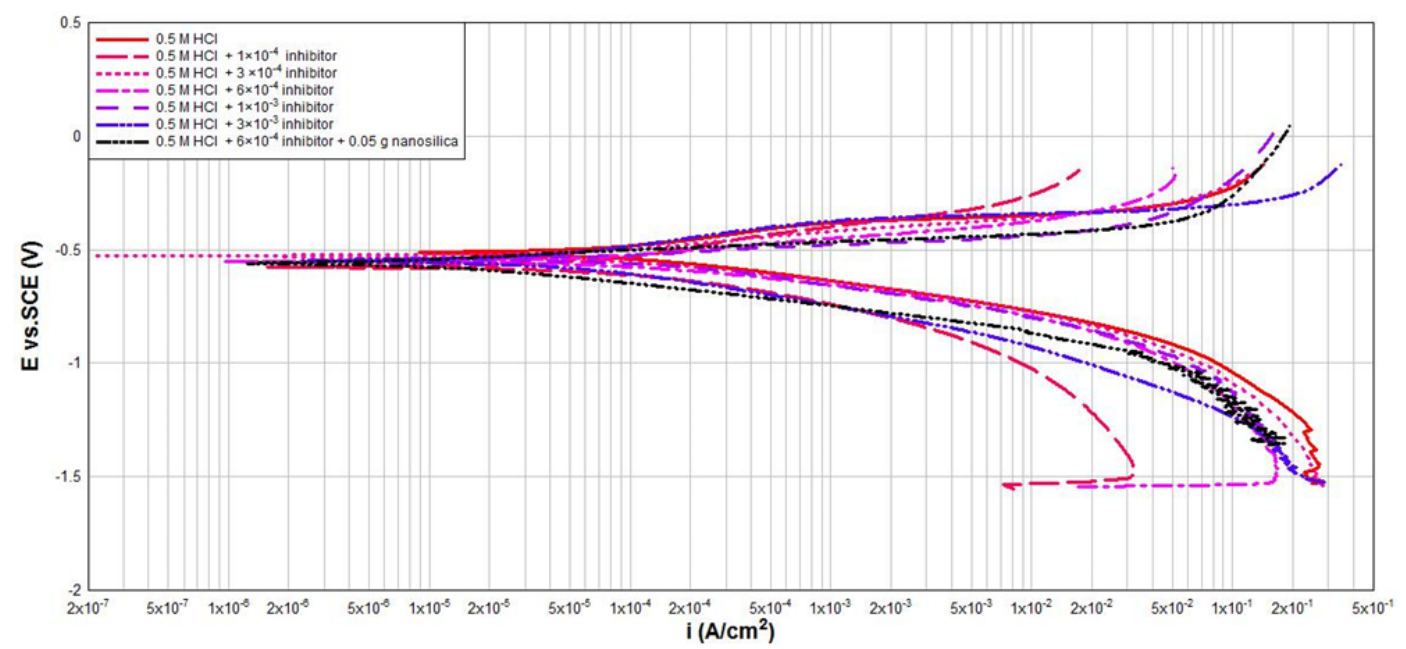

Figure 3. The potentiodynamic polarization curves of carbon steel in deaerated $0.5 \mathrm{M} \mathrm{HCl}$ with and without cupral inhibitor as well as in the presence of silica nanoparticles at $298.15 \mathrm{~K}$

The extent of this displacement in the values of the OCP indicates that inhibitor molecules instantaneously impact both the cathodic and anodic processes, i.e, the organic compounds can be classified as a cathodic and/or an anodic inhibitor (Oguzie, E. E. et al., 2007) and necessitates to change in the values of OCP with the additive's inhibitor with reference to the blank acidic solution. Thus, the variation in the OCP and corrosion potential values are clearly shown in Table 2 and displacements in potential values of up to $\sim 23 \mathrm{mv}$ are shown under the same conditions in the presence of inhibitor and nanosilicate additive. This indicates the influence of anodic and cathodic reactions and retards these reactions with respect to the OCP conditions (De Souza \& Spinelli, 2009). Furthermore, only slight shifts are observed between the corrosion potential $\mathrm{E}_{\text {cor }}$ and OCP values upon the addition of the cupral molecules. This behaviour indicates that the energetic effects are strong, but may ignore the blocking effect on the electrode surface (Martinez \& Metikoš-Huković, 2003). Regarding the polarization curves exhibited in Figures 2 and 3, it can be observed that the corrosion potentials values drift to a more negative direction in the presence of cupral and with the addition of the silica nanoparticles at a fixed concentration of inhibitor.

Table 2. The kinetic parameters as well as inhibition efficiency of carbon steel in deaerated $0.5 \mathrm{M} \mathrm{HCl}$ and 0.25 $\mathrm{M} \mathrm{H}_{2} \mathrm{SO}_{4}$ in different concentrations of cupral inhibitor and in the presence of $\mathrm{SiO}_{2}$ nanoparticle at $298.15 \mathrm{~K}$

\begin{tabular}{|c|c|c|c|c|c|c|c|c|c|}
\hline $\begin{array}{l}\text { Acidic } \\
\text { Medium }\end{array}$ & $\begin{array}{l}\text { Conc.inh. } \\
\text { (M) }\end{array}$ & $\begin{array}{l}\text { Ocp. } \\
(\mathrm{mV})\end{array}$ & $\begin{array}{c}\mathrm{i}_{\text {Corr }} \\
\left(\mu \mathrm{A} / \mathrm{cm}^{2}\right)\end{array}$ & $\begin{array}{l}E_{\text {Corr }} \\
(\mathrm{mV})\end{array}$ & $\begin{array}{c}\beta_{\mathrm{a}} \\
\text { (mV/decade) }\end{array}$ & $\begin{array}{c}\beta_{\mathrm{C}} \\
\text { (mV/decade) }\end{array}$ & $\begin{array}{c}\text { corrosion } \\
\text { rate } \\
(\mathrm{mpy})\end{array}$ & $\% \mathrm{IE}$ & $\theta$ \\
\hline \multirow{8}{*}{$\begin{array}{l}0.25 \mathrm{M} \\
\mathrm{H}_{2} \mathrm{SO}_{4}\end{array}$} & 0 & $\begin{array}{l}-533 \\
\end{array}$ & 256.0 & -511.0 & 50.80 & 134.4 & 95.12 & --- & --- \\
\hline & $1 \times 10^{-4}$ & -574 & 77.10 & -542.0 & 50.20 & 108.7 & 51.60 & 69.88 & 0.69 \\
\hline & $3 \times 10^{-4}$ & -571 & 69.80 & -550.0 & 49.40 & 89.00 & 25.90 & 72.73 & 0.72 \\
\hline & $6 \times 10^{-4}$ & -563 & 31.30 & -544.0 & 40.20 & 78.30 & 11.64 & 87.77 & 0.87 \\
\hline & $1 \times 10^{-3}$ & -540 & 17.00 & -553.0 & 52.30 & 79.70 & 6.326 & 93.35 & 0.93 \\
\hline & $3 \times 10^{-3}$ & -539 & 7.540 & -551.0 & 51.90 & 62.70 & 2.799 & 97.05 & 0.97 \\
\hline & \multicolumn{9}{|c|}{$0.05 \mathrm{~g}$ silica nanoparticles } \\
\hline & $6 \times 10^{-4}$ & -560 & 6.720 & -568.0 & 42.80 & 84.40 & 2.493 & 97.3 & 0.97 \\
\hline \multirow{8}{*}{$\begin{array}{c}0.5 \mathrm{M} \\
\mathrm{HCl}\end{array}$} & 0 & -528 & 100.0 & -516.0 & 155.0 & 121.0 & 37.12 & --- & --- \\
\hline & $1 \times 10^{-4}$ & -552 & 74.70 & -577.0 & 184.9 & 123.3 & 27.74 & 25.3 & 0.25 \\
\hline & $3 \times 10^{-4}$ & -536 & 64.30 & -527.0 & 96.10 & 92.80 & 23.89 & 35.7 & 0.35 \\
\hline & $6 \times 10^{-4}$ & -541 & 56.10 & -552.0 & 83.10 & 76.40 & 20.82 & 43.9 & 0.43 \\
\hline & $1 \times 10^{-3}$ & -545 & 47.00 & -541.0 & 46.30 & 74.60 & 17.45 & 53.0 & 0.53 \\
\hline & $3 \times 10^{-3}$ & -525 & 38.30 & -547.0 & 137.6 & 123.4 & 14.23 & 61.7 & 0.61 \\
\hline & \multicolumn{9}{|c|}{$0.05 \mathrm{~g}$ silica nanoparticles } \\
\hline & $6 \times 10^{-4}$ & -556 & 5.600 & -559.0 & 43.50 & 66.80 & 2.079 & 94.4 & 0.94 \\
\hline
\end{tabular}


These results are in agreement with the open circuit potential values in Table 2 and confirm the influence of the organic inhibitor in retarding the corrosion reaction by the adsorption process and subsequent blocking of active sites on the surface electrode (De Souza \& Spinelli, 2009), (Martinez \& Metikoš-Huković, 2003). The corrosion current density decreased considerably and a greater shift is observed in $0.25 \mathrm{M} \mathrm{H}_{2} \mathrm{SO}_{4}$ when compared with 0.5 $\mathrm{M} \mathrm{HClacidic} \mathrm{solutions} \mathrm{with} \mathrm{increasing} \mathrm{concentration} \mathrm{of} \mathrm{cupral} \mathrm{and} \mathrm{with} \mathrm{the} \mathrm{addition} \mathrm{of} \mathrm{silica} \mathrm{nanoparticles} \mathrm{at} \mathrm{a}$ particular inhibitor concentration. The variation in anodic and cathodic Tafel slope constants were observed as the inhibitor concentration was varied and significant changes were observed in the cathodic Tafel constants. This change also clearly includes an anodic slope constant in the presence of $\mathrm{SiO}_{2}$ nanoparticles, demonstrating interference in the reaction mechanism for corrosion at the cathode in the presence of the inhibitor (De Souza \& Spinelli, 2009). This behaviour reflects the fact that the cupral inhibitor acts as mixed type inhibitor and mainly controls the cathodic reaction through retarding the evolution of hydrogen and is exclusively reduced by the blocking effect (Martinez \& Metikoš-Huković, 2003). However, in the presence of nanosilica in acidic solution it seems clear that the action of mixed control is prevalent on the anodic and the cathodic reactions. Moreover, when increasing the concentration of the cupral inhibitor, the values of the corrosion current densities are decreased so that the extent of the decline becomes more pronounced in the presence of the $\mathrm{SiO}_{2}$ nanoparticles to reach $\sim 5 \mu \mathrm{A} / \mathrm{cm}^{2}$.

$$
I E \%=\left(\frac{i_{\text {corr. uninh. }}-i_{\text {corr. inh. }}}{i_{\text {corr. uninh. }}}\right) \times 100
$$

The inhibition efficiencies are estimated independently of the corrosion current density, with $\left(i_{\text {corr.inh. }}\right)$ and without ( $i_{\text {corr.uninh. }}$ ) the cupral inhibitor, according to equation (Özcan et al., 2004), (Şahin et al., 2002) and shows the corrosion efficiencies increase with increasing the inhibitor concentration in different acidic solutions. For a given inhibitor concentration, the values of corrosion efficiencies are higher in sulfuric acid when compared to the hydrochloric acid and the maximum value occurs at $3 \times 10^{-3} \mathrm{M}$. It can also be observed that the degree of corrosion inhibition changes strongly in the presence of silica nanoparticles to reach $94.4 \%$ within the corrosive hydrochloric acid medium as illustrated in Table 2. Thus, it might interpreted that cupral is an excellent inhibitor for controlling the corrosion process in sulfuric acid solution and it has been found that the addition of silica nanoparticles enhances the inhibitory effect towards corrosion and leads to an increase in the values of corrosion inhibition efficiency. This finding is consistent with decreasing the corrosion rate and the corrosion current density.

\subsection{Adsorption Isotherm}

The results of these experiments were designed to derive basic information about the interaction between the inhibitor molecules and the surface of carbon steel by classifying the type of adsorption isotherms observed. Commonly, the organic inhibitor could work through physical adsorption or chemisorption with the surface of metal (Fuchs-Godec \&Pavlovi, 2012). To obtain more information about the interaction between the surface and the inhibitor, it was tested using a different adsorption isotherm. So, the coverage surface $\theta$ of electrode in a various concentrations of cupral inhibitor in $0.25 \mathrm{M} \mathrm{H}_{2} \mathrm{SO}_{4}$ and $0.5 \mathrm{M} \mathrm{HCl}$ acidic solutions were calculated by the potentiodynamic polarization measurements according to equation (2) (Moretti et al., 2004) as shown in Table (2).

$$
\theta=\left(\frac{i_{\text {corr. uninh. }}-i_{\text {corr. inh. }}}{i_{\text {corr. uninh. }}}\right)
$$

Thus, to study the interaction between the electrode surface of carbon steel and cupral inhibitor a number of adsorption models were selected to study the interactions that would characterize the cupral performance. It is essential to calculate the experimental adsorption isotherms, which are best fitted to the data for the surface coverage in order to use these measurements of potentiodynamic scans to calculate the thermodynamic parameters relating to inhibitor adsorption. Models that were deemed successful were used (Umoren et al., 2007), (Ibrahim et al., 2012) and the graphical plots are shown in Figure 4.

$$
\begin{aligned}
& \text { Langmuir } \frac{C_{\text {inh. }}}{\theta}=\frac{1}{\mathrm{~K}_{\mathrm{ads} .}}+\mathrm{C}_{\mathrm{inh} .} \\
& \text { Freundlich } \theta=\mathrm{K}_{\text {ads. }} \mathrm{C}_{\mathrm{inh} .}{ }^{\frac{1}{n}} \\
& \text { Temkin } \exp (f \cdot \theta)=\mathrm{K}_{\text {ads. }} \mathrm{C}_{\mathrm{inh} .}
\end{aligned}
$$




$$
\text { El-awady } \frac{\theta}{1-\theta}=K_{\text {ads. }} C_{\text {inh. }}{ }^{\mathrm{y}}
$$

The definition of the parameters in equations (3-6) are as follows: $\mathrm{K}_{\text {ads. }}$ refers to the equilibrium constant, $\mathrm{C}_{\mathrm{inh}}$, the concentrations of cupral inhibitor, $\mathrm{n}$; the adsorption intensity, $f$ the uniformity coefficient energetic and yequal $1 / \mathrm{x} ; \mathrm{x}$ is the number of $\mathrm{H}_{2} \mathrm{O}$ molecules that are displaced by one cupral molecule. Thus, we get the best fit for straight lines when the Langmuir equation is applied and a linear relationship results with good correction coefficient ( $\mathrm{r} 2$ ). In sulfuric acid solution the value $\mathrm{r}^{2}=0.999$ and the slope is exactly equal to unity, but in hydrochloric acid solution under the same conditions, $\mathrm{r}^{2}=0.998$ and the slope is 1.523 . So, the data from the experiments conducted on the cupral inhibitor for the adsorption on the surface electrode of carbon steel obeyed the Langmuir equation for the adsorption process as shown in Figure 4.

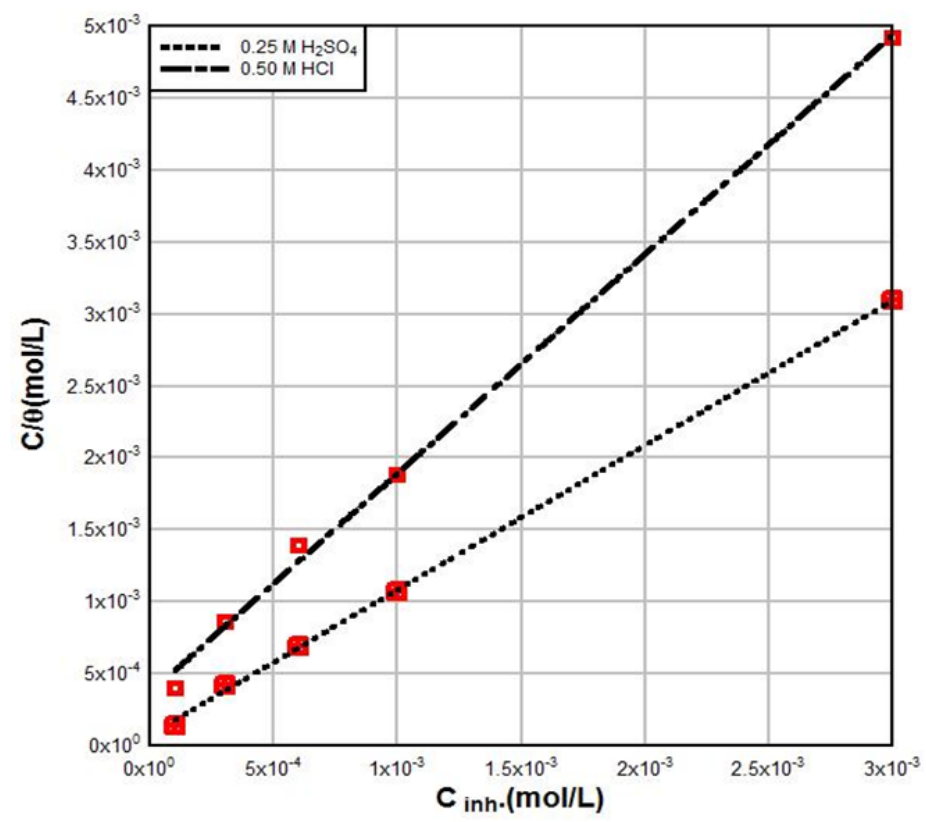

Figure 4. Langmuir adsorption plots of carbon steel in deaerated $0.25 \mathrm{M} \mathrm{HCl}$ and $0.5 \mathrm{M} \mathrm{H}_{2} \mathrm{SO}_{4}$ solutions at $298.15 \mathrm{~K}$

Thus, the deviation of the slope from unity implies that the Langmuir isotherm model may be not firmly applied and is attributed to the natural interactions that occur on the surface electrode between the molecules (species) of the adsorbate and the metal of carbon steel (Oguzie et al., 2005), (Oguzie et al., 2004b). Other authors have indicated that this behaviour results in a change in the heat of adsorption that corresponds to an increase in $\theta$ degree which is not considered in the Langmuir equation (Oguzie et al., 2004a),(E E Oguzie et al., 2007). Furthermore, the important thermodynamic parameters, such as $\mathrm{K}_{\mathrm{ads}}$, may be calculated from the intercept of equation and the value of free energy of adsorption by equation (7). Consideration of these data gives a clear vision for the interactions occurring between the inhibitor molecules and the surface of carbon steel (Solmaz et al., 2008).

$$
\Delta G_{a d s}=-R T \ln \left(55.5 K_{a d s}\right)
$$

The values of $\mathrm{K}_{\mathrm{ads}}$. and $\Delta \mathrm{G}_{\mathrm{ads}}$ are $1.27 \times 10^{4} \mathrm{M}-1$ and $-33.4 \mathrm{~kJ}$ mol-1 respectively for steel in deaerated 0.25 M H2SO4 acidic solution, while $2.72 \times 10^{3} \mathrm{M}-1$ and $-29.6 \mathrm{~kJ}$ mol-1 in $0.5 \mathrm{M} \mathrm{HCl}$ solution. Firstly, the negative value for the change in the free energy of the adsorption process indicates its spontaneity as well as implying the stability of the adsorbed layer that has formed on the surface of the carbon steel (Solmaz et al., 2008), (Martinez \& Stern, 2002). Typically, when the value of free energy of adsorption is near $-20 \mathrm{~kJ}$ mol-1 it shows that the electrostatic forces or interactions are established between the surface of metal and the charges of inhibitor molecules. On the other hand, if the value of $\Delta G_{a d s} \geq-40 \mathrm{~kJ}$ mol-1 it corresponds to chemical adsorption to form coordinates type bonds which form the basis of electron transfer and sharing between the inhibitor molecules with the metal (Bouklah et al., 2006). In this case, the values of $\Delta \mathrm{G}_{\mathrm{ads}}$ lie in range $-29.6 \mathrm{~kJ}$ mol-1 to $-33.4 \mathrm{~kJ}$ mol-1, and therefore, the absorption mechanism of cupral on the surface of the carbon steel 
electrode is predominantly through chemical adsorption from the deaerated $0.25 \mathrm{M} \mathrm{H}_{2} \mathrm{SO}_{4}$ and the $0.5 \mathrm{M} \mathrm{HCl}$ acidic solutions. However, Moretti et al. and Abiola et al. have reported values of free energy for the adsorption process which were less than the value required for chemical adsorption, indicating that physisorption occurred through the formation of protective films on the surface of the carbon steel with characteristics of electrostatic interactions (Moretti et al., 2004), (Abiola \& Oforka, 2004). Thus, one can visualize the coordinate bond type through the donation of unpaired electron on the sulfur and nitrogen and may be via the $\pi$ - electron of a double bond noted in Figure 2.

\subsection{The Effect of Temperature}

By estimating the activation energy of the corrosion process in the presence of the cupral inhibitor it is possible to understand the mechanism of inhibition. Thus, the independent potentiodynamic measurements, which were achieved over a range of temperature $(298.15-318.15) \mathrm{K}$, were recorded in $0.25 \mathrm{M} \mathrm{H}_{2} \mathrm{SO}_{4}$ and $0.5 \mathrm{M} \mathrm{HCl}_{\text {acidic }}$ solutions containing the optimum concentration of the cupral inhibitor and the results are listed in Table 3 . There is not much change in the general shape of the Tafel scan when the temperature was increased over the range and the data obtained in the figures are practically the same as those illustrated in Figures 1and 2. It can be seen from the Table 3, that the corrosion current density and the corrosion rate decreased with respect to a particular temperature value, while the corrosion potential values in $0.25 \mathrm{M} \mathrm{H}_{2} \mathrm{SO}_{4}$ acidic solution are shifted less in the negative direction in contrast to the more corrosive $0.5 \mathrm{M} \mathrm{HCl}$ solution. In the same context, the values of \% IE decreased in $0.25 \mathrm{M} \mathrm{H}_{2} \mathrm{SO}_{4}$ when compared with the $0.5 \mathrm{M} \mathrm{HCl}$ solutions as temperature was increased over the range.

Table 3. The kinetic parameters as well as inhibition efficiency of carbon steel in deaerated $0.5 \mathrm{M} \mathrm{HCl}$ and 0.25 $\mathrm{M} \mathrm{H}_{2} \mathrm{SO}_{4}$ in $3 \times 10^{-3} \mathrm{M}$ of cupral inhibitor in range of temperatures $(298.15-318.15) \mathrm{K}$

\begin{tabular}{|c|c|c|c|c|c|c|c|}
\hline $\begin{array}{l}\text { Acidic Medium } \\
\text { / Conc. inh. } \\
\text { (M) }\end{array}$ & $\begin{array}{l}\text { Temp. } \\
(\mathrm{K})\end{array}$ & $\begin{array}{c}\mathrm{i}_{\text {Corr }} \\
\left(\mu \mathrm{A} / \mathrm{cm}^{2}\right)\end{array}$ & $\begin{array}{l}E_{\text {Corr. }} \\
(\mathrm{mV})\end{array}$ & $\begin{array}{c}\beta_{\mathrm{a}} \\
\text { (mV/decade) }\end{array}$ & $\begin{array}{c}\beta_{\mathrm{c}} \\
\text { (mV/decade) }\end{array}$ & $\begin{array}{l}\text { corrosion } \\
\text { rate } \\
\text { (mpy) }\end{array}$ & $\% \mathrm{IE}$ \\
\hline \multirow{4}{*}{$0.25 \mathrm{M} \mathrm{H}_{2} \mathrm{SO}_{4}$} & 298.15 & 256.0 & -511.0 & 50.80 & 134.4 & 95.12 & -- \\
\hline & 308.15 & 83.40 & -562.0 & 73.30 & 105.1 & 30.84 & --- \\
\hline & 313.15 & 196.0 & -554.0 & 180.1 & 187.6 & 72.61 & --- \\
\hline & 318.15 & 177.0 & -550.0 & 266.6 & 253.6 & 65.45 & --- \\
\hline \multirow{4}{*}{$\begin{array}{c}0.25 \mathrm{M} \mathrm{H}_{2} \mathrm{SO}_{4}+ \\
3 \times 10^{-3}\end{array}$} & 298.15 & 7.540 & -551.0 & 51.90 & 62.70 & 2.799 & 97.05 \\
\hline & 308.15 & 14.00 & -528.0 & 37.50 & 57.20 & 5.175 & 83.21 \\
\hline & 313.15 & 46.00 & -531.0 & 90.10 & 72.10 & 17.03 & 76.53 \\
\hline & 318.15 & 70.90 & -532.0 & 97.00 & 76.20 & 26.23 & 59.94 \\
\hline \multirow{4}{*}{$0.5 \mathrm{M} \mathrm{HCl}$} & 298.15 & 100.0 & -516.0 & 155.0 & 121.0 & 37.12 & --- \\
\hline & 308.15 & 104.0 & -569.0 & 109.8 & 115.3 & 38.42 & --- \\
\hline & 313.15 & 383.0 & -527.0 & 156.6 & 98.00 & 141.8 & --- \\
\hline & 318.15 & 844.0 & -514.0 & 126.0 & 101.3 & 312.3 & --- \\
\hline \multirow{4}{*}{$\underset{3 \times 10^{-3}}{0.5 \mathrm{M} \mathrm{HCl}}+$} & 298.15 & 38.30 & -547.0 & 137.6 & 123.4 & 14.23 & 61.70 \\
\hline & 308.15 & 12.70 & -568.0 & 53.00 & 75.10 & 4.697 & 87.78 \\
\hline & 313.15 & 73.30 & -547.0 & 153.9 & 93.80 & 27.11 & 80.86 \\
\hline & 318.15 & 122.0 & -549.0 & 242.2 & 113.6 & 45.19 & 85.54 \\
\hline
\end{tabular}

This behaviour indicates an increase in the rate of dissolution of the carbon steel as a result of the desorption of the cupral molecules from the surface of the carbon steel electrode (Quraishi et al., 2010). The modified Arrhenius equation, as well the transition state equation, were applied independently to give the logarithm of corrosion current density over the temperature to determine the $\Delta \mathrm{E}_{\mathrm{a}}, \Delta \mathrm{H}^{*}$ and $\Delta \mathrm{S}^{*}$ values, respectively (Ghasemi \& Tizpar, 2006), (Yurt et al., 2004) and are given below:

$$
\begin{gathered}
\log i_{\text {corr. }}=\frac{-E_{a}}{2.302 R T}+\log A \\
\log \frac{i_{\text {corr. }}}{T}=\frac{R T}{N h} \exp \left(\frac{\Delta S^{*}}{R}\right) \exp \left(-\frac{\Delta H^{*}}{R T}\right)
\end{gathered}
$$

Where the $\mathrm{A}$ is a pre-exponential factor, $\mathrm{E}_{\mathrm{a}}$ the apparent activation energy, $\mathrm{N}$ is Avogadro's number, $\mathrm{h}$ is the 
Planck's constant, $\Delta \mathrm{H}^{*}$ is the apparent enthalpy of activation and $\Delta \mathrm{S}^{*}$ is the apparent entropy of activation. The linear relationship obtained from the graph arising from equation (8) was plotted as $\log i_{\text {corr. }}$ versus $\frac{1}{T}$, with the slope equal to $\frac{-\mathrm{E}_{\mathrm{a}}}{2.302 \mathrm{R}}$. The plot of the values of $\log \frac{\mathrm{i}_{\text {corr. }}}{\mathrm{T}}$ versus $\frac{1}{\mathrm{~T}}$ gave a straight line with a slope $-\frac{\Delta \mathrm{H}^{*}}{2.303 \mathrm{R}} \quad$ and the intercept as a $\log \left(\frac{\mathrm{R}}{\mathrm{Nh}}\right)+\Delta \mathrm{S}^{*} / 2.303 \mathrm{R}$.. The kinetic parameters such as $\mathrm{E}_{\mathrm{a}}, \Delta \mathrm{H}^{*}$ and $\Delta \mathrm{S}^{*}$ are tabulated (Table 4) and shown graphically in Figures 3 and 5.

Table 4. Kinetic corrosion and thermodynamic parameters in deaerated $0.5 \mathrm{M} \mathrm{HCl}$ and $0.25 \mathrm{M} \mathrm{H}_{2} \mathrm{SO}_{4}$ solutions in with and without $3 \times 10^{-3} \mathrm{M}$ of cupral inhibitor in range of temperatures (298.15-318.15) $\mathrm{K}$

\begin{tabular}{cccccc}
\hline & Acidic Medium (M) & $\begin{array}{c}\mathrm{A} \\
\mathrm{A} \mathrm{cm}^{-2}\end{array}$ & $\begin{array}{c}\Delta \mathrm{E}_{\mathrm{a}} \\
\mathrm{kJ} \mathrm{mol}^{-1}\end{array}$ & $\begin{array}{c}\Delta \mathrm{H}^{*} \\
\mathrm{~kJ} \mathrm{~mol}^{-1}\end{array}$ & $\begin{array}{c}\Delta \mathrm{S}^{*} \\
\mathrm{~J} \mathrm{~mol}^{-1} \mathrm{~K}^{-1}\end{array}$ \\
\hline \multirow{2}{*}{$0.25 \mathrm{M}$} & $\mathrm{H}_{2} \mathrm{SO}_{4}+3 \times 10^{-3}$ cupral inhibitor & $2.478 \times 10^{-06}$ & -10.79600 & -13.353311 & -206.093 \\
$0.5 \mathrm{M} \mathrm{HCl}$ & $4.850 \times 10^{10}$ & 91.83556 & 89.27826 & -189.5920 \\
$0.5 \mathrm{M} \mathrm{HCl}+3 \times 10^{-3}$ cupral inhibitor & 8551.94400 & 48.97872 & 46.72888 & -189.8700 \\
& & & & &
\end{tabular}

From Table 4 it is clear that the activation energy has a high value in the inhibited system in $0.25 \mathrm{M} \mathrm{H}_{2} \mathrm{SO}_{4}$ solution, whereas this is in contrast with the case involving $0.5 \mathrm{M} \mathrm{HCl}$ acidic solution under the same conditions, which is in agreement with the corrosion inhibition at the elevated range of temperature (Popova et al., 2003). That is to say, that the \% IE in $0.25 \mathrm{M} \mathrm{H}_{2} \mathrm{SO}_{4}$ acidic solution decreases when the temperature increases, this behaviour is interpreted as the physisorption happening at the first stage (Zarrouk et al., 2014),(Benabdellah et al., 2006) and this is correlated with increasing the electrical double layer thickness which encloses the surface carbon steel electrode. This establishment of this formation yields a high value for the activation energy and leads to hindrance of metal dissolution by forming a protective film. The high activation energy reflects the enhanced inhibitory action, notably at low temperatures (Chauhan \& Gunasekaran, 2007). The negative value of $\Delta \mathrm{E}_{\mathrm{a}}$ of the uninhibited $0.25 \mathrm{M} \mathrm{H}_{2} \mathrm{SO}_{4}$ solution suggests that the experimentally calculated activation energy of corrosion is apparent, i.e. $E_{a}=E_{a p p}$. Thus, the true energy of activation $E_{\text {true }}$ can be given by the expression, $E_{\text {app }}=E_{\text {true }}+\Delta H$, for this a highly exothermic reaction and when the value of $E_{\text {true }}$ is small one might expect the $E_{a}$ value to be negative (Zhang et al., 2012). Thus, the values of activation energy are higher than the enthalpy of activation as shown in Table 3 which refers to the evolution of hydrogen gas and is related to the reduction in the total volume of hydrogen evolution in the cathodic process (Hassan, 2007), (Ekanem et al., 2010). Besides, the difference between the activation energy and the enthalpy of activation remain in range of (2-3) $\mathrm{kJ} \mathrm{mol}^{-1}$ i.e. approaching the average value of the absolute gas constant when multiplied by the degree of temperature. This behaviour suggests that the corrosion reaction is unimolecular in nature (Ekanem et al., 2010). It is clear from equation (8) that the corrosion current density that is achieved can be determined by the activation energy and the pre-exponential factor. That is, the value of A may refers to the number of the active sites on the surface of the electrode as alluded to by some researchers (Ashassi-Sorkhabi et al., 2005), (Popova et al., 2007). Thus, the variation in the pre-exponential factor and the values of $\Delta \mathrm{E}_{\mathrm{a}}$ have a dominant influence when estimating the kinetics of the corrosion process.

In the present work, except in the case of unhibited system of $0.25 \mathrm{M} \mathrm{H}_{2} \mathrm{SO}_{4}$ solution, it is clear the value of A decreases in the presence of cupral inhibitor, which is associated with a reduction in the number of active sites (Singh, 2012) and lowers the rate of corrosion. This explains the sharper decline in the pre-exponential in $0.25 \mathrm{M}$ $\mathrm{H}_{2} \mathrm{SO}_{4}$ for the uninhibited solution as the decisive factor that influences the rate of corrosion for carbon steel in corrosive media with respect to the value of $\Delta \mathrm{E}_{\mathrm{a}}$ that it shown in Table 4. 


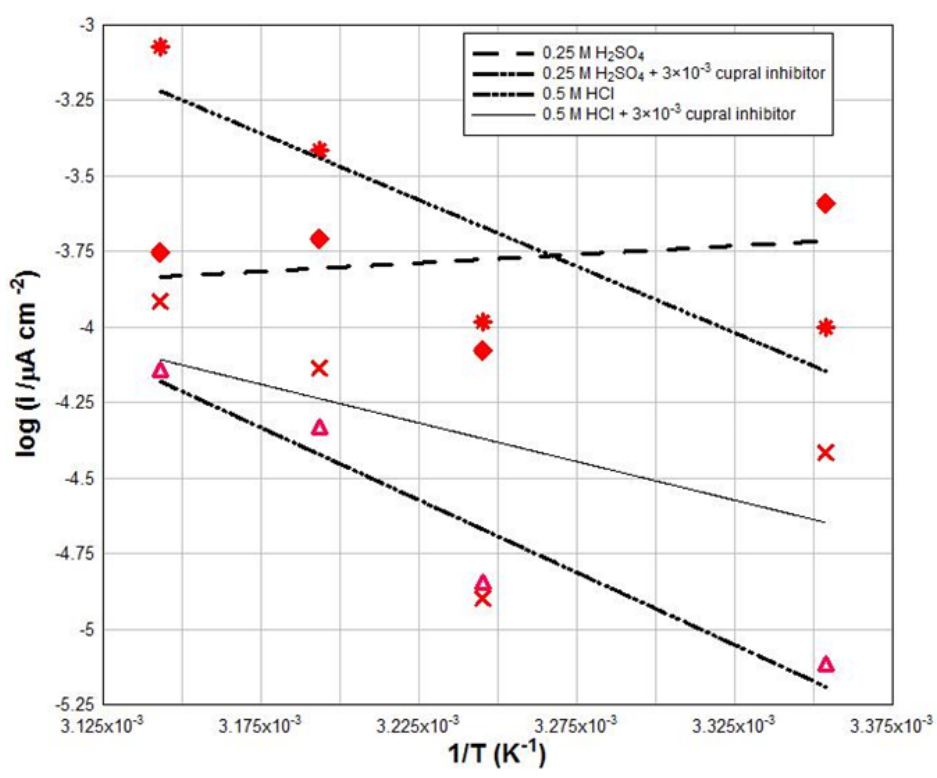

Figure 5. Arrhenius plots of carbon steel in the absence and the presence $3 \times 10^{-3} \mathrm{M}$ of cupral in deaerated $0.25 \mathrm{M}$ $\mathrm{HCl}$ and $\mathrm{H}_{2} \mathrm{SO}_{4}$ solutions

Regarding the thermodynamic parameters for the activation state as a $\Delta \mathrm{H}^{*}$ and $\Delta \mathrm{S}^{*}$, and compared with the data in Table 3, it can be seen the enthalpy of activation has a positive value, which it suggest dissolution of carbon steel electrode is an endothermic reaction, requiring energy, whereas in contrast value is negative in the $0.25 \mathrm{M} \mathrm{H}_{2} \mathrm{SO}_{4}$ solution, an exothermic corrosion process. Furthermore, the values of entropy for the activation state were negative, the shifts in the values of $\Delta \mathrm{S}^{*}$ from -206.093 to $189.592 \mathrm{~J} \mathrm{~mol}^{-1} \mathrm{~K}^{-1}$ reveal the reduction in disorder that comes from the reactants at the expense of activated complex, i.e. the dissolution process is no longer dominant in the rate of determining step of the activation complex (Martinez and Stern, 2002), (Obot and Obi-Egbedi, 2010). Our results are similar to other found in the literature (Singh, 2012), (Mu et al., 2004).

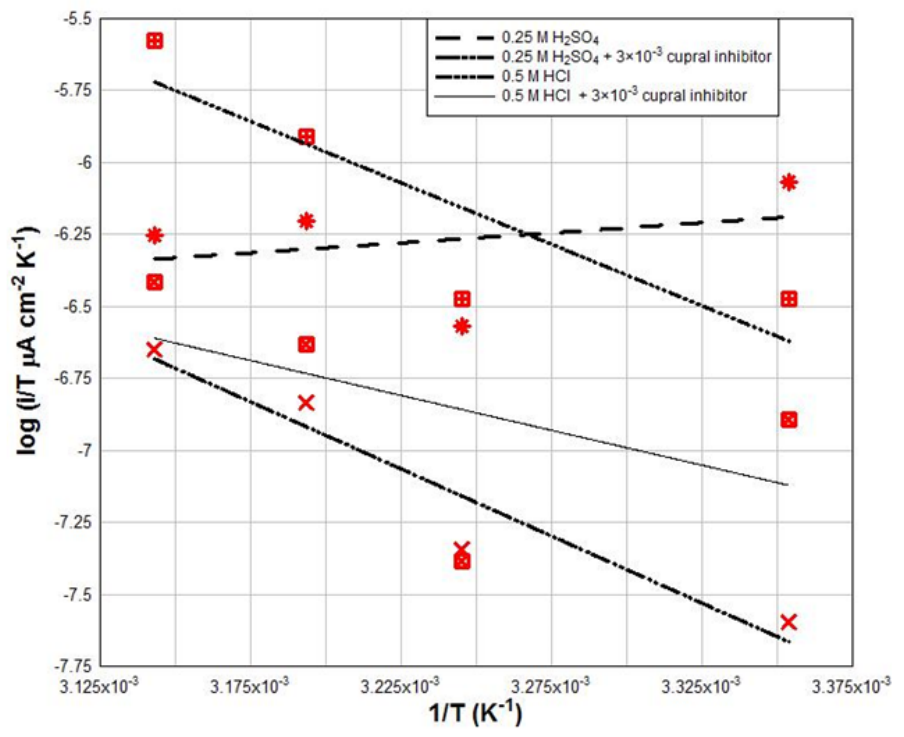

Figure 6. Plot of variation $\log \left(\mathrm{i} / \mathrm{T} \mu \mathrm{A} \mathrm{cm}^{-2} \mathrm{~K}^{-1}\right)$ versus $1 / \mathrm{T}\left(\mathrm{K}^{-1}\right)$

\subsection{Surface Characterization (ESM/EDX and AFM)}

A combination of techniques was used to characterize the surface: images were obtained from scanning electron microscopy (SEM) and data were generated using energy dispersive $\mathrm{x}$-ray (EDX) measurements, and atomic force microscopy (AFM). Using this combination, it was possible to give the clear vision of the nature of the 
inhibition of corrosion in the presence of certain concentrations of nanosilica with the cupral inhibitor in the 0.25 $\mathrm{M} \mathrm{H}_{2} \mathrm{SO}_{4}$ and $0.5 \mathrm{M} \mathrm{HCl}$ solutions as depicted in Figures 7a-d. Figure 7a shows the image of the sample present in the $0.5 \mathrm{M} \mathrm{HCl}$ corrosive medium, the surface seems more damaged and appears to be pitted while there is a crack which appears to display wavy lines characteristic of the electrode surface. Additionally, the surface colour ranges from grey to black, characteristic of a $\mathrm{Fe}_{3} \mathrm{C}$ film (S. Nesic, 1994) and the chemical analysis of EDX shows the iron content to be about $79.5 \%$ and the carbon to be $20.5 \%$ in the carbon steel electrode. Figure $4 \mathrm{~b}$ illustrates the system containing $\left(0.5 \mathrm{M} \mathrm{HCl}+0.05 \mathrm{~g}\right.$ nanosilica $+6 \times 10^{-4} \mathrm{M}$ cupral $)$, and the surface of the electrode seems to have sustained less damage in aggressive medium, due to the disappearance of the pitting and cracking with the formation of a very pale grey film. There is underscoring of the protective layer on the electrode surface and this causing an improvement in the integrity of the surface. Considering the composition obtained from the EDX analysis, it appears that other elements such as copper and oxygen are present, the latter at $10.7 \%$ which may be a result of the silica nanoparticles which are spread on the surface. These also tend to suppress the iron content to $68.3 \%$. Likewise, Figure $7 \mathrm{c}$ shows the ESM image and the data from the EDX measurement in the presence of the corrosive $0.25 \mathrm{M} \mathrm{H}_{2} \mathrm{SO}_{4}$ solution. Overall, the attack seems less severe resulting from the sulfuric acid, the pits appear less deep and are less evident on the surface of the electrode when compared with Figure 7a. The EDX results yield an iron content of $64 \%$ and carbon of $33.8 \%$. Furthermore, inspection of Figure 7d, suggests that the surface is more protected from the aggressive attack of the sulfuric acid in the presence of nanosilica and the $6 \times 10^{-4} \mathrm{M}$ cupral with an improved electrode surface as a result of the protective layer formed from the adsorbed molecules. The EDX analysis is consistent with the strengthened protection layer and appears to show more lines of elements of different intensities and content: oxygen $12.8 \%$, sulfur $1.5 \%$. The latter arises from the cupral molecules, along with bands that arose from the original alloy components. The SEM images and EDX charts are consistent with the electrochemical studies that suggest the carbon steel surface is protected through the cupral inhibitor via the adsorption process. This is thought to block the central active site and retard the dissolution of the metal and curb the evolution of hydrogen while the role of the nanosilica is to enhance and increase the corrosion resistance by reducing the corrosion current density as mentioned in potentiodynamic polarization curves in above section.
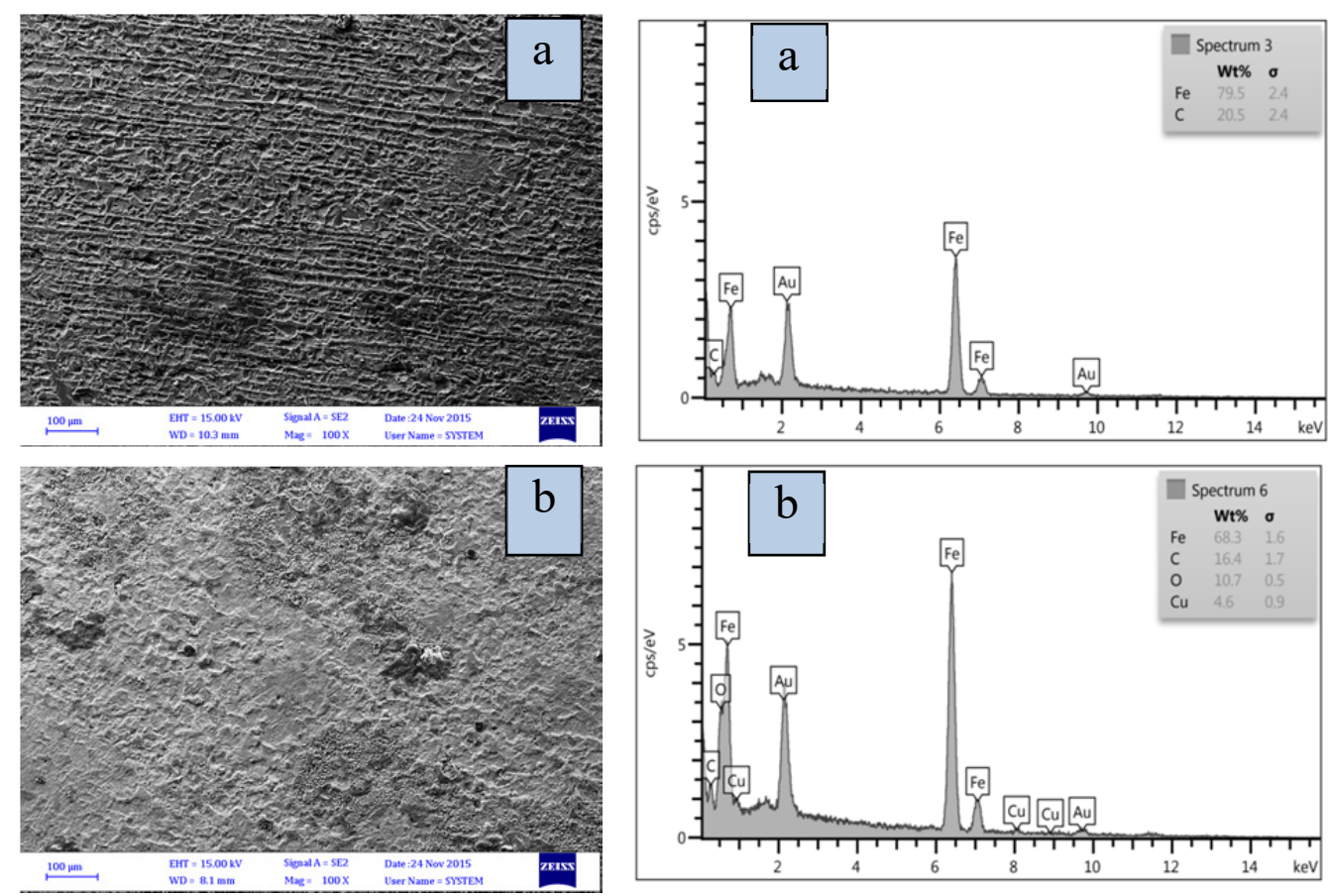

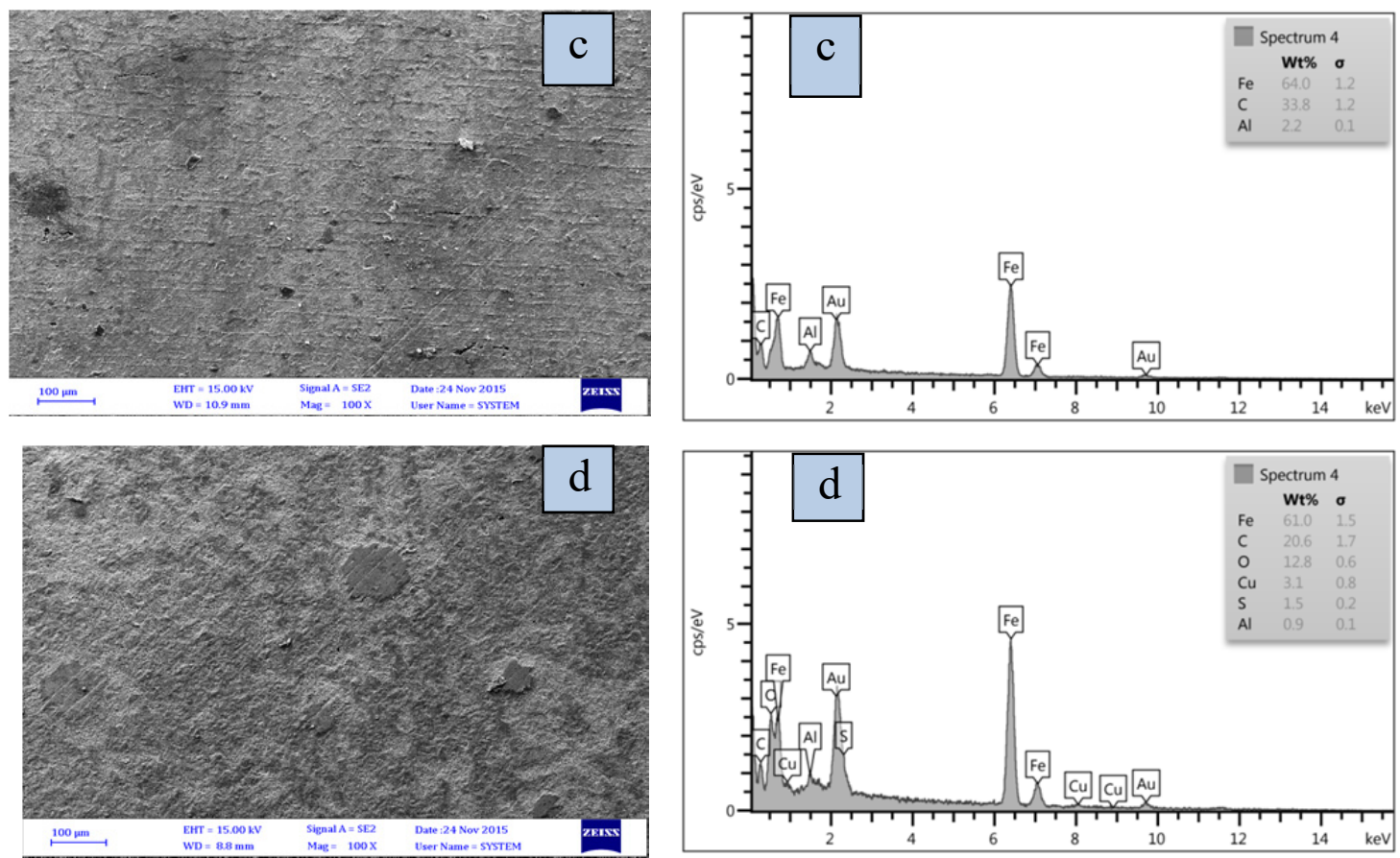

Figure 7. The SEM and EDS for the carbon steel electrode surface in (a ) $0.5 \mathrm{M} \mathrm{HCl}$ and (b) The presence of silica nanoparticles with cupral inhibitor in hydrochloric acid solution (c) $0.25 \mathrm{M} \mathrm{H}_{2} \mathrm{SO}_{4}$ and (d) Silica nanoparticles with cupral inhibitor in $0.25 \mathrm{M} \mathrm{H}_{2} \mathrm{SO}_{4}$ at $298.15 \mathrm{~K}$

AFM is an important technique used to evaluate the morphology of the electrode surface to give a clear perception of the inhibition of corrosion. The 2D and 3D dimensional AFM images portray the samples in both aggressive media $\left(0.25 \mathrm{M} \mathrm{H}_{2} \mathrm{SO}_{4}\right.$ and $0.5 \mathrm{M} \mathrm{HCl}$ solutions) in the presence of the $6 \times 10^{-4} \mathrm{M}$ cupral containing a certain amount of nanosilicate particles as shown in Figures 8a-e. It can be seen from Figure 8a that the polished surface of the uncorroded carbon steel electrode seems to display a topology that has a high order of regularity and uniformity. However, one may notice a slim groove which results from the polishing process by using sandpaper sheets - the average roughness parameter $\left(\mathrm{R}_{\mathrm{a}}\right)$ is found to be $23.3 \mathrm{~nm}$. In the presence of the aggressive media (in the absence of additives) the average roughness $\mathrm{R}_{\mathrm{a}}$ is found to $73.3 \mathrm{~nm}$ in $0.25 \mathrm{M} \mathrm{H}_{2} \mathrm{SO}_{4}$ and $71.1 \mathrm{~nm}$ in $0.5 \mathrm{M} \mathrm{HCl}$ solutions respectively. The surface appears to be covered with potholes and the topography has steeply sided surface irregularities with a few more notches and grooves evident; the uneven shape is clearly illustrated in Figures 8b, c. Figure 8d depicts similar for samples containing the cupral inhibitor and nanosilica $(0.5 \mathrm{~g})$ in sulfuric acid. In contrast, the surface topology appeared more regular and smooth; lacking the deep gullies, i.e., the surface seems less convoluted, so that $R_{a}$ is now $7.25 \mathrm{~nm}$. Likewise, the roughness parameter which was obtained following exposure to the hydrochloric acid solution is $43 \mathrm{~nm}$ in the presence of cupral and the nanosilica. There is also apparently less surface damage in comparison with previous samples; the existence and effect of the protons and the chloride ions form a protective adsorbent layer on the surface to give the necessary protection of the surface electrode as demonstrated in Figure 8e. 

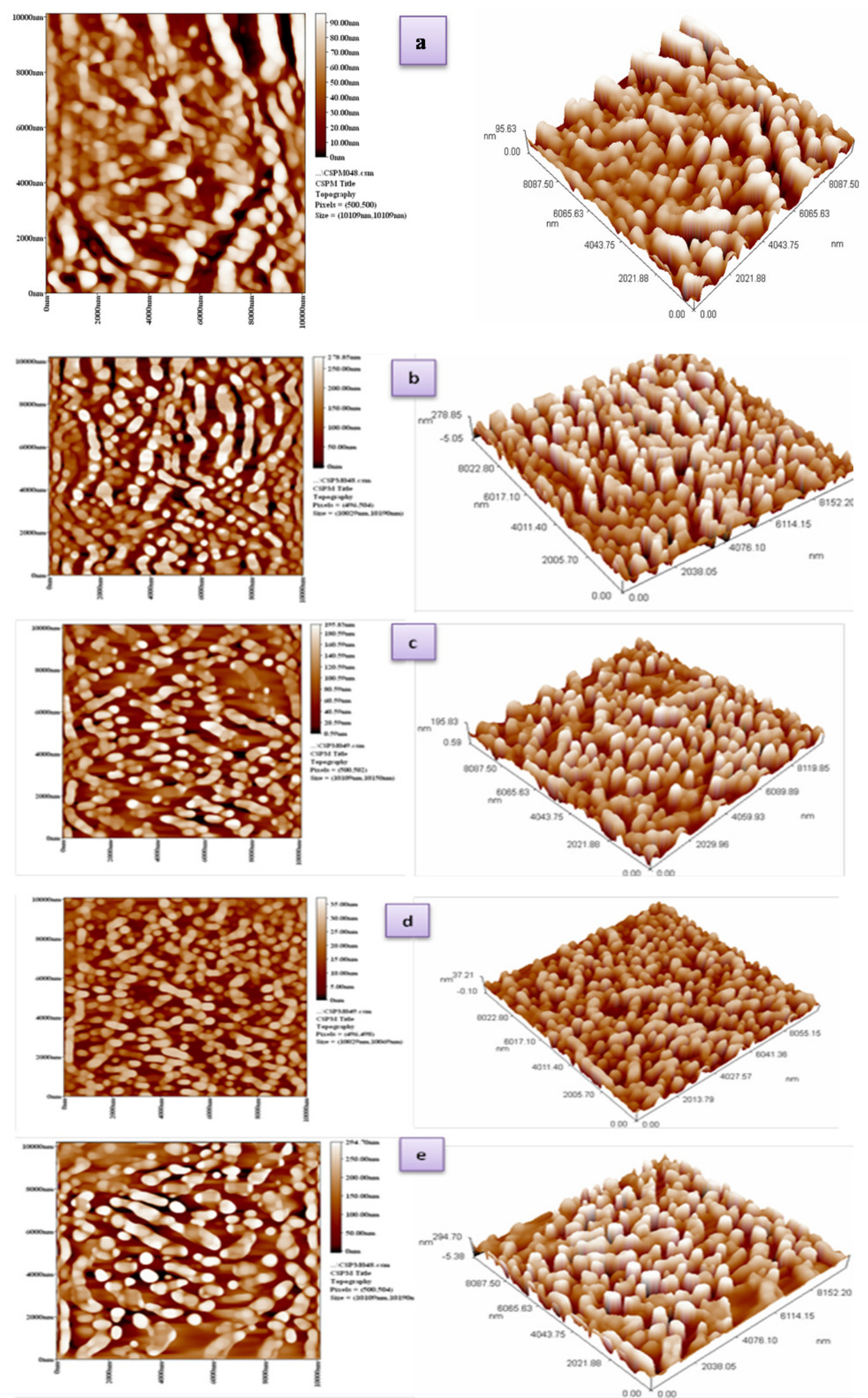

Figure 8. The AFM images in 2D and 3D of polish the carbon steel surface (a), $0.5 \mathrm{M} \mathrm{HCl}$ (b) With silica nanoparticles and cupral inhibitor(c), $0.25 \mathrm{M} \mathrm{H}_{2} \mathrm{SO}_{4}(\mathrm{~d})$ and in the presence of silica nanoparticles in $0.5 \mathrm{M}$ sulfuric acid solution (e) 


\subsection{Inhibition Mechanism of Corrosion}

To forecast the mechanism by which inhibition occurs for the adsorption of molecules on the surface of carbon steel, the corrosion mechanism of metals must first be known. Some searchers have proposed the following mechanism for the corrosion of carbon steel in acidic solution, where equations (10-13) represent the anodic reaction and equations (14-16) refer to the cathodic reaction. The letters $\mathrm{M}, \mathrm{A}$ and $\mathrm{N}$ represent a metal (iron), acid and the number of electrons, respectively (Quraishi et al., 2010) (Singh, 2012).

$$
\begin{gathered}
\mathrm{M}+\mathrm{A}^{\mathrm{n}-} \rightleftharpoons\left(\mathrm{MA}^{\mathrm{n}-}\right)_{\text {ads. }} \\
\left(\mathrm{MA}^{\mathrm{n}-}\right)_{\text {ads. }} \rightleftharpoons\left(\mathrm{MA}^{\mathrm{n}-}\right)_{\text {ads. }}+\mathrm{ne}^{-} \\
\left(\mathrm{MA}^{\mathrm{n}-}\right)_{\text {ads. }} \rightarrow\left(\mathrm{MA}^{\mathrm{n}+}\right)_{\text {ads. }}+\mathrm{ne}^{-} \\
\left(\mathrm{MA}^{\mathrm{n}+}\right)_{\text {ads. }} \rightleftharpoons\left(\mathrm{M}^{++}\right)_{\text {ads. }}+\mathrm{A}^{\mathrm{n}-} \\
\mathrm{M}+\mathrm{H}^{+} \rightleftharpoons\left(\mathrm{MH}^{+}\right)_{\text {ads. }} \\
\left(\mathrm{MH}^{+}\right)_{\text {ads. }}+\mathrm{ne}^{-} \rightarrow(\mathrm{MH})_{\text {ads. }} \\
\left(\mathrm{MH}^{+}\right)_{\text {ads. }}+\mathrm{H}^{+}+\mathrm{ne}^{-} \rightarrow \mathrm{M}+\mathrm{H}_{2}
\end{gathered}
$$

The phenomenon of the adsorption of molecules of cupral on solid surfaces cannot be regarded purely as physical adsorption or purely chemisorption. Herein lies the importance of the thermodynamic factors such as the Gibbs free energy of adsorption which was previously determined in the two acidic solutions. The results demonstrate that the adsorption of inhibitor is enhanced: in first stage physical adsorption is observed and chemical adsorption occurs sequentially. Figure 1 shows the molecular structure of inhibitor, wherein it can be observed that the sulfur and nitrogen heteroatoms have electron lone pairs (not involved in the formation of covalent bonds) as well the electron density in the double bond ( $\pi$-electron). The non-bonded electron pairs could be shared with the vacant $d$-orbital in the iron atoms to yield a coordinate bond, on the basis of the Lewis base/acid (electron acceptor and donor) phenomenon (Behpour et al., 2008), (Mehdi et al., 2002). Thus, the sticking feature which performed the corrosion inhibition i.e. the number of sulfur atoms that formed the $d_{\pi}-d_{\pi}$ chemical bonds, occurs through the overlap between the vacant orbital in the sulfur atom and the three electrons in the $d$-orbital in the iron atom (Jafari et al., 2014). One can also distinguish another type of electronic overlap to form a further bond by back donation of the electron density of the double bond that forms between the $d$-orbital of the metal and the $\pi^{*}$ - orbital (Ahamad et al., 2010). Moreover, the role of the nanosilicate nanoparticles in involved in improving the stability of the protective layer formed on the surface of the carbon steel electrodes. Furthermore, it may be concluded independently from the above results which demonstrate that the protection efficiency was higher in $0.25 \mathrm{M} \mathrm{H}_{2} \mathrm{SO}_{4}$ acidic medium than the $0.5 \mathrm{M} \mathrm{HCl}$ solution, indicating to the role of the sulphate ion is to form an adsorbed species $\left(\mathrm{FeSO}_{4}^{-2}\right)_{\text {ads. }}$ according to the equation (10) and as $\left(\mathrm{FeCl}^{-}\right)_{\text {ads. }}$. That is to say, according to equations (11-13), the subsequent oxidation process for the above adsorbed species leads to the release of sulfate and chloride ions, respectively. Thus, one knows intuitively that chloride ions are more harmful for the metal compared with sulfate ions. One might also expect that the mechanism is prevented in other way according to the equations (11-13). If protonation of the cupral molecules occurs then the availability of excess negative charge on the surface electrode (Singh and Quraishi, 2011) will become associated with the protective layer as $\left(\mathrm{MCl}^{-1}\right.$ cupral $\left.{ }^{+}\right)$ads. or $\left(\mathrm{MSO}_{4}^{-2} \text { cupral }{ }^{+}\right)_{\text {ads. }}$. Likewise, competition may occur between the (cupral ${ }^{+}$) and $\mathrm{H}^{+}$in cathodic process according to equations (14-16) to reduce the evolution of hydrogen gas.

\section{Conclusion}

Cupral was studied as a corrosion inhibitor for (X65-steel) carbon steel in deaerated $0.25 \mathrm{M} \mathrm{H}_{2} \mathrm{SO}_{4}$ and $0.5 \mathrm{M}$ $\mathrm{HCl}$ acidic solutions. It was also examined in combination with a certain amount of silica nanoparticles, the results indicate the inhibitor works well to prevent and inhibit the corrosion process in sulfuric acid. Under the same conditions, the corrosion efficiency was increased with increasing inhibitor concentration; on the other hand, the polarization scan measurements confirmed the type of inhibitor as having mixed action for the cathodic and anodic reactions. The protective film layer, which formed on the surface of the carbon steel electrode, was characterized by SEM/EDX and AFM techniques. The values of thermodynamic and corrosion kinetics parameters were estimated to give a clear vision on the adsorption of inhibitor molecules on the electrode surface.

\section{References}

Abiola, O. K., \& Oforka, N. C. (2004). Adsorption of (4-amino-2-methyl-5-pyrimidinyl methylthio) acetic acid 
on mild steel from hydrochloric acid solution (HCl), Part 1. Mater. Chem. Phys., 83, 315-322. http://dx.doi.org/10.1016/j.matchemphys.2003.10.001

Ahamad, I., Prasad, R., \& Quraishi, M. A. (2010). Inhibition of mild steel corrosion in acid solution by pheniramine drug: Experimental and theoretical study. Corros. Sci., 52, 3033-3041. http://dx.doi.org/10.1016/j.corsci.2010.05.022

Alaoui, Mouayd, A., Orazem, M. E., Sutter, E. M. M., Tribollet, B., \& Koltsov, A. (2014). Contribution of electrochemical dissolution during pickling of low carbon steel in acidic solutions. Corros. Sci., 82, 362368. http://dx.doi.org/10.1016/j.corsci.2014.01.036

Aljinovi, L., Gudi, S., \& Mith, M. (2000). Inhibition of CuNi10Fe corrosion in seawater by sodium-diethyl-dithiocarbamate: An electrochemical and analytical study. J. Appl. Electrochem, 30, 973979. http://dx.doi.org/10.1023/A:1004074405514

Ashassi-Sorkhabi, H., Shaabani, B., \& Seifzadeh, D. (2005). Corrosion inhibition of mild steel by some Schiff base compounds in hydrochloric acid. Appl. Surf. Sci., 239, 154-164.

Badawy, W. A., Ismail, K. M., \& Fathi, A. M. (2006). Corrosion control of Cu-Ni alloys in neutral chloride solutions by amino acids. Electrochim. Acta., 51, 4182-4189. http://dx.doi.org/10.1016/j.electacta.2005.11.037

Behpour, M., Ghoreishi, S. M., Salavati-Niasari, M., \& Ebrahimi, B. (2008). Evaluating two new synthesized S-N Schiff bases on the corrosion of copper in 15\% hydrochloric acid. Mater. Chem. Phys., 107, 153-157. http://dx.doi.org/10.1016/j.matchemphys.2007.06.068

Benabdellah, M., Aouniti, A., Dafali, A., Hammouti, B., Benkaddour, M., Yahyi, A., \& Ettouhami, A. (2006). Investigation of the inhibitive effect of triphenyltin 2-thiophene carboxylate on corrosion of steel in $2 \mathrm{M}$ H3PO4 solutions. Appl. Surf. Sci., 252, 8341-8347. http://dx.doi.org/10.1016/j.apsusc.2005.11.037

Bouklah, M., Hammouti, B., Lagrene, M., \& Bentiss, F. (2006). Thermodynamic properties of 2, 5-bis (4-methoxyphenyl)-1,3,4-oxadiazole as a corrosion inhibitor for mild steel in normal sulfuric acid medium. Corros. Sci., 48, 2831-2842. http://dx.doi.org/10.1016/j.corsci.2005.08.019

Chauhan, L. R., \& Gunasekaran, G. (2007). Corrosion inhibition of mild steel by plant extract in dilute $\mathrm{HCl}$ medium. Corros. Sci., 49, 1143-1161. http://dx.doi.org/10.1016/j.corsci.2006.08.012

D'Ars de Figueiredo, J. C., de F. C., Lins, V., \& de Bellis, V. M. (2013). Inhibiting effect of dithiocarbamate on TM 23 bronze alloy corrosion in acid medium. Corros. Eng. Sci. Technol., 48, 288-293. http://dx.doi.org/10.1179/1743278212Y.0000000075

de Souza, F. S., \& Spinelli, A. (2009). Caffeic acid as a green corrosion inhibitor for mild steel. Corros. Sci., 51, 642-649. http://dx.doi.org/10.1016/j.corsci.2008.12.013

Ekanem, U. F., Umoren, S. A., Udousoro, II., \& Udoh, A. P. (2010). Inhibition of mild steel corrosion in HCl using pineapple leaves (Ananas comosus L.) extract. J. Mater. Sci., 45, 5558-5566. http://dx.doi.org/10.1007/s10853-010-4617-y

Fuchs-Godec, R., \& Pavlovi, M. G. (2012). Synergistic effect between non-ionic surfactant and halide ions in the forms of inorganic or organic salts for the corrosion inhibition of stainless-steel X4Cr13 in sulphuric acid. Corros. Sci., 58, 192-201. http://dx.doi.org/10.1016/j.corsci.2012.01.027

Ghasemi, Z., \& Tizpar, A. (2006). The inhibition effect of some amino acids towards Pb-Sb-Se-As alloy corrosion in sulfuric acid solution. Appl. Surf. Sci., 252, 3667-3672. http://dx.doi.org/10.1016/j.apsusc.2005.05.043

Hassan, H. H. (2007). Inhibition of mild steel corrosion in hydrochloric acid solution by triazole derivatives. Part II: Time and temperature effects and thermodynamic treatments. Electrochim. Acta, 53, 1722-1730. http://dx.doi.org/10.1016/j.electacta.2007.08.021

Ibrahim, T., Alayan, H., \& Mowaqet, Y. Al. (2012). The effect of Thyme leaves extract on corrosion of mild steel in HCl. Prog. Org. Coatings, 75, 456-462. http://dx.doi.org/10.1016/j.porgcoat.2012.06.009

Jafari, H., Akbarzade, K., \& Danaee, I. (2014). Corrosion inhibition of carbon steel immersed in a $1 \mathrm{M} \mathrm{HCl}$ solution using benzothiazole derivatives. Arab. J. Chem., 1-8. http://dx.doi.org/10.1016/j.arabjc.2014.11.018

Jawich, M. W. S., Oweimreen, G. A., \& Ali, S. A. (2012). Heptadecyl-tailed mono- and bis-imidazolines: A study 
of the newly synthesized compounds on the inhibition of mild steel corrosion in a carbon dioxide-saturated saline medium. Corros. Sci., 65, 104-112. http://dx.doi.org/10.1016/j.corsci.2012.08.001

Li, L., Zhang, X., Lei, J., He, J., Zhang, S., \& Pan, F. (2012). Adsorption and corrosion inhibition of Osmanthus fragran leaves extract on carbon steel. Corros. Sci., 63, 82-90. http://dx.doi.org/10.1016/j.corsci.2012.05.026

Li, Y., \& Fedkiw, P. S. (2007). Effect of gel electrolytes containing silica nanoparticles on aluminum corrosion. Electrochim. Acta, 52, 2471-2477. http://dx.doi.org/10.1016/j.electacta.2006.08.066

Liao, Q. Q., Yue, Z. W., Yang, D., Wang, Z. H., Li, Z. H., Ge, H. H., \& Li, Y. J. (2011). Inhibition of copper corrosion in sodium chloride solution by the self-assembled monolayer of sodium diethyldithiocarbamate. Corros. Sci., 53, 1999-2005. http://dx.doi.org/10.1016/j.corsci.2011.02.023

Martinez, S., \& Metikoš-Huković, M. (2003). A nonlinear kinetic model introduced for the corrosion inhibitive properties of some organic inhibitors. J. Appl. Electrochem., 33, 1137-1142. http://dx.doi.org/10.1023/B:JACH.0000003851.82985.5e

Martinez, S., \& Stern, I. (2002). Thermodynamic characterization of metal dissolution and inhibitor adsorption processes in the low carbon steel/mimosa tannin/sulfuric acid system. Appl. Surf. Sci., 199, 83-89. http://dx.doi.org/10.1016/S0169-4332(02)00546-9

Mehdi, B. El., Mernari, B., Traisnel, M., Bentiss, F., \& Lagrenée, M. (2002). Synthesis and comparative study of the inhibitive effect of some new triazole derivatives towards corrosion of mild steel in hydrochloric acid solution. 77, 489-496.

Morad, M. S. (2008). Inhibition of iron corrosion in acid solutions by Cefatrexyl: Behaviour near and at the corrosion potential. Corros. Sci., 50, 436-448. http://dx.doi.org/10.1016/j.corsci.2007.08.018

Moretti, G., Guidi, F., \& Grion, G. (2004). Tryptamine as a green iron corrosion inhibitor in $0.5 \mathrm{M}$ deaerated sulphuric acid. Corros. Sci., 46, 387-403. http://dx.doi.org/10.1016/S0010-938X(03)00150-1

Mu, G. N., Li, X., \& Li, F. (2004). Synergistic inhibition between o-phenanthroline and chloride ion on cold rolled steel corrosion in phosphoric acid. Mater. Chem. Phys., 86, 59-68. http://dx.doi.org/10.1016/j.matchemphys.2004.01.041

Nesic, S. L. L. (1994). Carbon Dioxide Corrosion of Carbon Steel in Two-Phase Flow. Corros. Sci., 50, 717-727. http://dx.doi.org/10.5006/1.3293548

Obayes, H. R., Alwan, G. H., Alobaidy, A. H. M., Al-Amiery, A. A., Kadhum, A. A. H., \& Mohamad, A. B. (2014). Quantum chemical assessment of benzimidazole derivatives as corrosion inhibitors. Chem. Cent. J., 8,21 . http://dx.doi.org/10.1186/1752-153X-8-21

Obot, I. B., \& Obi-Egbedi, N. O. (2010). Adsorption properties and inhibition of mild steel corrosion in sulphuric acid solution by ketoconazole: Experimental and theoretical investigation. Corros. Sci., 52, 198 204. http://dx.doi.org/10.1016/j.corsci.2009.09.002

Oguzie, E. E., Li, Y., \& Wang, F. H. (2007). Effect of 2-amino-3-mercaptopropanoic acid (cysteine) on the corrosion behaviour of low carbon steel in sulphuric acid. Electrochim. Acta, 53, 909-914. http://dx.doi.org/10.1016/j.electacta.2007.07.076

Oguzie, E. E., Li, Y., Wang, F. H. (2007). Corrosion inhibition and adsorption behavior of methionine on mild steel in sulfuric acid and synergistic effect of iodide ion. J. Colloid Interface Sci., 310, 90-98.

Oguzie, E. E., Okolue, B. N., Ebenso, E. E., Onuoha, G. N., \& Onuchukwu, A. I. (2004a). Evaluation of the inhibitory effect of methylene blue dye on the corrosion of aluminium in hydrochloric acid. Mater. Chem. Phys., 87, 394-401. http://dx.doi.org/10.1016/j.matchemphys.2004.06.003

Oguzie, E. E., Onuoha, G. N., \& Onuchukwu, A. I. (2005). Inhibitory mechanism of mild steel corrosion in $2 \mathrm{M}$ sulphuric acid solution by methylene blue dye. Mater. Chem. Phys., 89, 305-311. http://dx.doi.org/10.1016/j.matchemphys.2004.09.004

Oguzie, E. E., Unaegbu, C., Ogukwe, C. N., Okolue, B. N., \& Onuchukwu, A. I. (2004b). Inhibition of mild steel corrosion in sulphuric acid using indigo dye and synergistic halide additives. Mater. Chem. Phys., 84, $363-$ 368. http://dx.doi.org/10.1016/j.matchemphys.2003.11.027

Okafor, P. C., Liu, C. B., Liu, X., \& Zheng, Y. G. (2010). Corrosion inhibition and adsorption behavior of imidazoline salt on N80 carbon steel in CO 2 -saturated solutions and its synergism with thiourea, 1367- 
1376. http://dx.doi.org/10.1007/s10008-009-0963-6

Ostovari, A., Hoseinieh, S. M., Peikari, M., Shadizadeh, S. R., \& Hashemi, S. J. (2009). Corrosion inhibition of mild steel in $1 \mathrm{M} \mathrm{HCl}$ solution by henna extract: A comparative study of the inhibition by henna and its constituents (Lawsone, Gallic acid,d-Glucose and Tannic acid). Corros. Sci., 51, 1935-1949. http://dx.doi.org/10.1016/j.corsci.2009.05.024

Özcan, M., Dehri, I., \& Erbil, M. (2004). Organic sulphur-containing compounds as corrosion inhibitors for mild steel in acidic media: Correlation between inhibition efficiency and chemical structure. Appl. Surf. Sci., 236, 155-164. http://dx.doi.org/10.1016/j.apsusc.2004.04.017

Panossian, Z., Almeida, N. L., de Sousa, R. M. F., Pimenta, G. S., \& Marques, L. B. S. (2012). Corrosion of carbon steel pipes and tanks by concentrated sulfuric acid: A review. Corros. Sci., 58, 1-11. http://dx.doi.org/10.1016/j.corsci.2012.01.025

Popova, A., Christov, M., \& Vasilev, A. (2007). Inhibitive properties of quaternary ammonium bromides of N-containing heterocycles on acid mild steel corrosion. Part II: EIS results. Corros. Sci., 49, 3290-3302. http://dx.doi.org/10.1016/j.corsci.2007.03.012

Popova, A., Sokolova, E., Raicheva, S., \& Christov, M. (2003). AC and DC study of the temperature effect on mild steel corrosion in acid media in the presence of benzimidazole derivatives. Corros. Sci., 45, 33-58. http://dx.doi.org/10.1016/S0010-938X(02)00072-0

Preethi Kumari, P., Shetty, P., \& Rao, S. A. (2013). Electrochemical measurements for the corrosion inhibition of mild steel in $1 \mathrm{M}$ hydrochloric acid by using an aromatic hydrazide derivative. Arab. J. Chem. http://dx.doi.org/10.1016/j.arabjc.2014.09.005

Quraishi, M. A., Singh, A., Singh, V. K., Yadav, D. K., \& Singh, A. K. (2010). Green approach to corrosion inhibition of mild steel in hydrochloric acid and sulphuric acid solutions by the extract of Murraya koenigii leaves. Mater. Chem. Phys., 122, 114-122. http://dx.doi.org/10.1016/j.matchemphys.2010.02.066

Şahin, M., Bilgiç, S., \& Yilmaz, H. (2002). The inhibition effects of some cyclic nitrogen compounds on the corrosion of the steel in $\mathrm{NaCl}$ mediums. Appl. Surf. Sci., 195, 1-7. http://dx.doi.org/10.1016/S0169-4332(01)00783-8

Shams El Din, A. M., Mohammed, R. A., \& Haggag, H. H. (1997). Corrosion inhibition by molybdate/polymaliate $\quad$ mixtures. $\quad$ Desalination, $114, \quad 85-95$. http://dx.doi.org/10.1016/S0011-9164(97)00157-4

Singh, A. K. (2012). Inhibition of Mild Steel Corrosion in Hydrochloric Acid Solution by 3-(4-(( Z )-Indolin-3-ylideneamino)phenylimino)indolin-2-one. In D. Eng., Chem. Res., 51, 3215-3223. http://dx.doi.org/10.1021/ie2020476

Singh, A. K., \& Quraishi, M. A. (2011). Adsorption properties and inhibition of mild steel corrosion in hydrochloric acid solution by ceftobiprole. J. Appl. Electrochem., 41, 7-18.

Solmaz, R., Kardacs, G., Culha, M., Yazici, B., \& Erbil, M. (2008). Investigation of adsorption and inhibitive effect of 2-mercaptothiazoline on corrosion of mild steel in hydrochloric acid media. Electrochim. Acta, 53, 5941-5952.

Umoren, S. A., Ebenso, E. E., Okafor, P. C., Ekpe, U. J., \& Ogbobe, O. (2007). Effect of halide ions on the corrosion inhibition of aluminium in alkaline medium using polyvinyl alcohol. J. Appl. Polym. Sci., 103, 2810-2816. http://dx.doi.org/10.1002/app.25446

Yurt, A., Balaban, A., Kandemir, S. U., Bereket, G., \& Erk, B. (2004). Investigation on some Schiff bases as HCl corrosion inhibitors for carbon steel. Mater. Chem. Phys., 85, 420-426. http://dx.doi.org/10.1016/j.matchemphys.2004.01.033

Zarrouk, A., Hammouti, B., Dafali, A., Bouachrine, M., Zarrok, H., Boukhris, S., \& Al-Deyab, S. S. (2014). A theoretical study on the inhibition efficiencies of some quinoxalines as corrosion inhibitors of copper in nitric acid. J. Saudi Chem. Soc., 18, 450-455. http://dx.doi.org/10.1016/j.jscs.2011.09.011

Zhang, T., Wang, D., Shao, Y., Meng, G., \& Wang, F. (2012). A new criterion to determine the critical pitting temperature (CPT) based on electrochemical noise measurement. Corros. Sci., 58, 202-210. http://dx.doi.org/10.1016/j.corsci.2012.01.026 


\section{Copyrights}

Copyright for this article is retained by the author(s), with first publication rights granted to the journal.

This is an open-access article distributed under the terms and conditions of the Creative Commons Attribution license (http://creativecommons.org/licenses/by/3.0/). 